\title{
Teaching the problem-solving process in a progressive or a simultaneous way: a question of making sense? ${ }^{1}$
}

\author{
Vanessa Hanin $^{\text {a }}$, Catherine Van Nieuwenhoven ${ }^{\mathrm{a}}$ \\ ${ }^{a}$ Université catholique de Louvain, Belgium \\ Article received 27 September 2017 / Revised 12 December / Accepted 10 August / available online 30 August
}

\begin{abstract}
Over the past two decades, the perennial low success rates of elementary students in math problem solving and the difficulties experienced by teachers in helping their students with this type of task has become quite a hot topic. In response, several instructional interventions aiming to develop an expert and reflexive approach to problem solving have been designed. However, these interventions are based on two contrasting teaching approaches, either teaching the components of the problem-solving process at the same time or teaching them one at the time. A meticulous analysis of the literature indicates that studies that have compared these two teaching approaches have focused primarily on undergraduate students. Moreover, they have mainly been assessed in terms of cognitive outcomes. Yet, recent studies stress the importance of analyzing the cognitive, motivational and emotional processes involved in problem-solving learning together in order to gain a full understanding of the process. Addressing these limitations is essential to enhance our understanding of problem-solving learning and to design more effective interventions. This paper focuses on this issue by investigating whether teaching the problem-solving process in all its complexity or one component at a time is preferable in terms of cognitive, motivational and emotional outcomes. This issue is handled for both novice and expert solvers. Data were gathered among 267 upper elementary students. Findings showed that both teaching approaches support the short-and long-term acquisition of cognitive problem-solving strategies, regardless of the student's profile. However, beneficial emotional and motivational outcomes occur only when the problem-solving process is taught in all its complexity, that is, makes sense for the learner. Novice solvers made less use of the help-seeking strategy and persisted more.
\end{abstract}

Keywords: Mathematics problem-solving; emotion regulation strategy; heuristic strategy; novice and expert; teaching practices

Corresponding author: Vanessa Hanin, Psychological Sciences Research Institute, Université catholique de Louvain, Place du Cardinal Mercier, 10, Louvain-la-Neuve, Belgium. E-mail: vanessa.hanin@uclouvain.be DOI : 10.14786/flr.v6i2.333

1 The authors disclosed receipt of the following financial support for the research, authorship, and/or publication of this article: This research was supported by grants from the Université catholique de Louvain (UCL). 


\section{Introduction}

In a societal context that lays increasing emphasis on the need for analytical and complex taskresolution skills (Depaepe, De Corte, \& Verschaffel, 2010; NTCM, 2010), it is important to question their development and acquisition in the academic context. In terms of mathematics education, curriculum designers have stressed that students develop meaningful mathematical skills, motivate themselves and learn how to deal appropriately with situations encountered in their everyday life through problem-solving tasks (NTCM, 2010). However, both research studies (Demonty, Blondin, Matoul, Baye, \& Lafontaine, 2013; Demonty \& Fagnant, 2014) and international tests (OECD, 2016) have brought to light students' perennial low success rates in math problem solving.

The alarming international test scores stimulated researchers to design educational interventions that aim to develop an expert and reflexive approach to problem solving. Most educational research (Blum, 2011; De Corte, 2012; Fagnant \& Jaegers, 2018; Tzohar-Rozen \& Kramarski, 2014) agrees that the development of an expert and reflexive approach to problem solving occurs through the mastery of specific heuristic strategies embedded in an overall metacognitive approach. Yet, different assumptions concerning the importance of facilitating realistic meaningful experiences, as opposed to facilitating cognitive processing, lead to different pedagogical approaches. On the one hand, research on the development of an expert and reflexive approach to mathematical problem solving conducted in the field of mathematics instruction stresses the importance of giving all students, whether they are experts or novices, realistic, meaningful, challenging and complex problem-solving tasks, supporting a "simultaneous" teaching approach (Blum, 2011; Depaepe et al., 2010; Van Dooren, Verschaffel, Greer, De Bock, \& Crahay, 2010). On the other hand, studies conducted in the field of cognitive psychology and, more specifically, anchored within the framework of cognitive load theory, have shown that, for novice learners, it is preferable to teach one element at a time to avoid overwhelming their working memory (Blayney, Kalyuga, \& Sweller, 2010; Pollock, Chandler, \& Sweller, 2002). Thus, if research in mathematics instruction supports approaching the problem-solving process in its full complexity, the work carried out in the field of cognitive psychology supports the opposite approach. In addition, there is a lack of understanding of the role of affective components and motivational aspects in the problem-solving process, as both of the traditions mentioned above focus (more or less widely) on cognitive aspects. Such understanding therefore appears crucial for the integration of the two approaches. And this is especially the case given that recent studies have pointed out the necessity of considering cognitive, emotional and motivational dimensions when dealing with teaching and learning issues (Ahmed, van der Werf, Kuyper, \& Minnaert, 2013; Pekrun, 2014; Tzohar-Rozen \& Kramarski, 2014).

The present study aims to extend previous research by overcoming these limitations and enhancing our understanding of the effects on cognitive, motivational and emotional dimensions of teaching the problemsolving process to upper elementary students. More precisely, this paper aims to test the effects of these two teaching approaches ("simultaneous" versus "gradual-all together") on the frequency of use of heuristic strategies, the valence of the emotions felt, the kind of emotion regulation strategies used and the level of persistence. In addition, given that novice and expert solvers may differ regarding their learning process, a comparison between the two teaching approaches was made for these two learner profiles (Muir, Beswick, \& Williamson, 2008; Zimmerman \& Campillo, 2003).

\section{Theoretical foundations and relevant empirical work}

First, we examine the problem-solving process. Then, the relation of cognitive load theory to the two teaching approaches studied in the present paper is described. Subsequently, the role played by emotions in problem-solving tasks and the necessity of developing functional emotion regulation strategies are examined. This section closes with discussion of one important motivational dimension for problem-solving learning, that is, persistence. 


\subsection{The problem-solving process}

Nowadays, scholars acknowledge that the development of expertise in mathematical problem solving requires the reconceptualization of mathematical problems as exercises in mathematical modeling; that is, considering the statement of a problem as the description of a situation in everyday life that can be modeled mathematically (Blum \& Niss, 1991; De Corte, Verschaffel, \& Masui, 2004; Fagnant, Demonty, \& Lejonc, 2003). Mathematical modeling is viewed as a complex and cyclic process involving a number of phases. In this regard, based on a thorough analysis of the existing literature in the problem-solving field (Blum, 2011; Fagnant \& Demonty, 2005; Fuchs, Fuchs, Prentice, Burch, Hamlett, et al., 2003 ; Lucangeli, Tressoldi, \& Cendron, 1998), Hanin and Van Nieuwenhoven (2016) identified, eight heuristic strategies ${ }^{2}$ of particular importance in solving non-routine problems that delineate the problem-solving process (Figure 1): (1) building a representation of the problem, that is, specifying the relevant contextual and numerical information, the unknown (what we are looking for), and the relationships between these elements via a drawing, a table or a reformulation (situation model); (2) estimating the answer a priori, that is, approximating the solution of the problem by identifying the kind of response that is needed (a measure, a price, etc.), by rounding the numbers, by imagining what the solution is not or by giving an order of magnitude; (3) using one's knowledge, namely, identifying the mathematical structure of the problem, asking whether one has already solved a similar problem and how one did it (identification of the mathematical model); (4) planning, that is, breaking down the problem into steps; (5) executing the necessary calculations, that is, translating each step of the solution plan by an appropriate mathematical operation and executing it to arrive at a final mathematical result; (6) verifying the relevance of the operations chosen, ensuring compliance with instructions and checking the accuracy of the calculations; (7) interpreting the outcome, that is, making sure that the solution makes sense with regard to the problem statement (plausibility of the solution) and that the solution is congruent with the a prior estimate; (8) for a satisfactory interpretation, the solution is communicated. The two teaching approaches compared in the present study are based on this problem-solving process. It should also be noted that the linear arrangement gives a timeline to be used in the teaching of the solving process. The problem-solving process must be seen as cyclical and constituted of a back-and-forth between the different heuristic strategies.

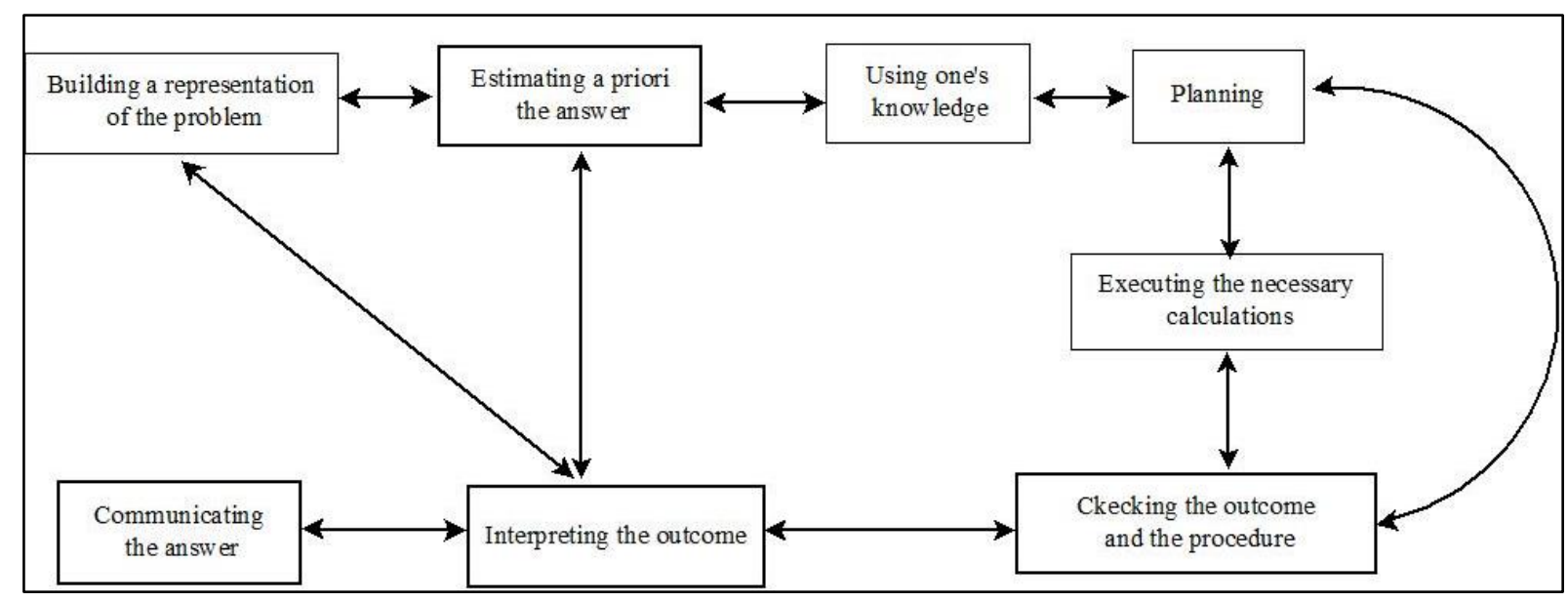

Figure 1. Schematic diagram of the problem-solving process

\footnotetext{
${ }^{2}$ Heuristic strategies are "search strategies for problem analysis and transformation which do not guarantee, but significantly increase the probability of finding the correct solution of a problem because they induce a systematic approach to the task" (De Corte et al., 2004, p.372).
} 


\subsection{The contribution of cognitive load theory}

Cognitive load theory views the resolution of complex, non-routine ${ }^{3}$ mathematical problems as high in element interactivity, where the elements are the heuristic strategies (Pollock et al., 2002; Van Merriënboer $\&$ Sweller, 2005). In such tasks students must process the different heuristic strategies in working memory simultaneously for learning to occur, since these heuristic strategies are all tightly linked. As many elements must be processed in working memory simultaneously, there is high intrinsic cognitive $\operatorname{load}^{4}$. Yet we know that working memory is limited. Usually the individual's cognitive architecture constructs schemas in order to handle the problem of working memory overload. Schemas organize a large number of elements and take their interactivity into account, while acting as a single element, that is, without overloading working memory. However, these schemas result from a preliminary construction. And therein lies the problem. The construction of such schemas is the result of the simultaneous processing of all of the elements and therefore includes the elements' interactivity. However, due to working memory limitations, novice ${ }^{5}$ learners can only process a few of the elements in working memory simultaneously, which prevents the construction of schemas, that is learning, from taking place. Thus, as processing all of the elements simultaneously in working memory is not effective (in the case of elements that are high in interactivity), there remains the option of processing element by element in working memory and thereby eliminating the interactions among them, but at the cost of a reduced understanding. On this point, empirical evidence has shown that it is more beneficial for non-expert learners to begin with a "one-by-one element" approach and, once each element has been examined in isolation, to deal with the full set of elements in an interactive way (what we call the "gradual-all together" approach) rather than to present, from the outset, the material in its full complexity (what we call the "simultaneous" approach) (Pollock et al., 2002; Van Merriënboer \& Sweller, 2005). Regarding expert learners, empirical studies have highlighted that they perform equally well regardless of the teaching approach used, because they already possess relevant problem-solving schemas (Pollock et al., 2002).

\subsection{The contribution of emotion theory}

Complex math tasks are known to generate negative emotions (Hanin, \& Van Nieuwenhoven, 2018; Op't Eynde, De Corte, \& Mercken, 2004). However, tasks lacking sufficient challenge also generate negative emotions, mostly boredom (Pekrun, Goetz, Daniels, Stupnisky, \& Perry, 2010). Thus, depending on the teaching approach implemented, both "novice" and "expert" problem-solvers might be affected by negative emotions. Negative emotions are known to be detrimental to learning. More precisely, studies have reported that negative emotions foster the use of rigid, detail-oriented, and analytical approaches, divert a part of the available cognitive resources from the task, and promote external regulation (Pekrun, 2014). Not only do students feel negative emotions when dealing with complex math problems but, in addition, they do not regulate these emotions (De Corte, Depaepe, Op't Eynde \& Verschaffel, 2011). On this point, Hanin et al. (2017) highlighted six strategies used by upper elementary school children to regulate their negative emotions when solving math problems. "Negative self-talk" involves focusing on the negative aspects of the situation, by dramatizing them, by constantly thinking them over or by convincing oneself that they are beyond one's control. "Dysfunctional avoidance" involves task avoidance, despite the fact that task completion is beneficial in the long run. "Emotion expression" refers to the social sharing of one's emotions. "Task utility selfpersuasion" involves convincing oneself of the personal utility of the task despite the fact that the task generates unpleasant emotions. "Help seeking" concerns seeking peer and teacher assistance. Finally, "brief

\footnotetext{
${ }^{3}$ The term "non-routine" is used to designate problems for which the solution does not appear immediately and for which the resolution is not based on the application of a procedure that was just seen in class (Elia, van den Heuvel-Panhuizen, \& Kolovou, 2009; Fagnant et al., 2003).

${ }^{4}$ Note that intrinsic cognitive load is to be distinguished from extraneous cognitive load. The former is imposed by the intellectual complexity of the information, while the latter results from the way the information is presented to the students (Pollock et al., 2002).

${ }^{5}$ Like several authors (Bassok, 2003; Brand, Reimer, \& Opwis, 2003), we use the terms "novice" and "expert" to designate students with poor and good word problem-solving skills, respectively. In this sense, it is a relative concept of “expert” and "novice” (Novick, 1988).
} 
attentional relaxation" involves releasing attention for a few seconds through distraction or relaxation. This strategy covers two sub-strategies, namely, a positive form of distraction and physical relaxation. Of these six, students considered the first three to be maladaptive and the other three were judged to be adaptive (Hanin, Gregoire, Mikolajczak, Fantini-Hauwel, \& Van Nieuwenhoven, 2017). However, although scholars agree on the crucial role played by emotions in problem-solving learning and performance, to our knowledge, no study so far has examined the effect of cognitive training programs on emotions and emotion regulation strategies.

\subsection{The contribution of motivation theory}

Alongside emotions, a motivational variable of particular interest when solving mathematical problems is persistence (Montague \& Applegate, 2000), that is, "the behavioral strength that fosters, despite the impediments encountered, the continuation of the actions required by the engagement" (Brault-Labbé \& Dubé, 2008, p. 731, our translation). Studies conducted by Montague and Applegate (2000) suggested that task difficulty has a direct influence on middle school students' persistence. They postulated that "some students "shut down" cognitively when they perceive problems as difficult or when information-processing demands seem excessive" (p. 225). Although little research has examined this concept in the context of compulsory schooling, on the basis of the above findings, we assume that learning all the heuristic strategies within the same problem-solving task, that is, as interactive, will raise more difficulties than learning them one at a time. Consequently, the "simultaneous" approach might undermine students' persistence, where the "gradual-all together" approach may have no effect or even support students' persistence. Nevertheless, no study has examined the effect on students' persistence of specific cognitive teaching approaches to problem solving.

\section{Aims and hypotheses}

This study investigates whether taking into account motivational and emotional dimensions leads to the same results as those observed in studies comparing the same two teaching methods but from a purely cognitive perspective. In other words, this study seeks to clarify the following question: "are the principles of cognitive load theory still valid when motivational and emotional dimensions come into play?".

This general issue is dealt with through two research aims. The first aim seeks to clarify whether it is better for learning to handle the problem-solving process in its full complexity - the "simultaneous" approach - or to teach one heuristic strategy at the time - the "gradual-all together" approach. Studies undertaken within the framework of cognitive load theory have stressed that the "simultaneous" approach consumes much more of the student's cognitive resources than the "gradual-all together" approach. Moreover, studies have also shown that complex tasks give rise to negative emotions. Therefore, we expected that the "gradual-all together" group would display a better understanding of the heuristic strategies taught, persist longer in the face of difficulties, feel fewer negative emotions, use appropriate emotion regulation strategies and perform better in problem solving than the "simultaneous" group ${ }^{6}$ and the control group (traditional approach) ${ }^{7}$.

The second aim examines whether it is appropriate to adopt a different teaching approach according to the learner's level of expertise in problem solving.

- Consistent with cognitive load theory, we hypothesized that the "gradual-all together" approach would lead to better learning outcomes for "novice" problem-solvers as compared to the "simultaneous" approach and the traditional approach. More precisely, we expected "novices" in the "gradual-all

\footnotetext{
${ }^{6}$ The three conditions are detailed in the section devoted to the training program.

${ }^{7}$ Teachers for the control group were selected on the basis of their traditional instructional practices for problem-solving consisting of brief individual reflection followed by collective correction carried out by the teacher.
} 
together" group to benefit more from the training program than their peers in the "simultaneous" and control groups.

- With regard to "expert" problem-solvers, as tasks lacking sufficient challenge are a source of negative emotions (Pekrun, 2014; Pekrun et al., 2010), we supposed that the "simultaneous" approach would suit them better.

These hypotheses were tested through the implementation of a cognitive training program in mathematical problem-solving (section 4.2).

As mentioned in the introduction, this comparison fits into a larger project. By examining the role of the motivational and emotional aspects of the problem-solving process, this paper also seeks to integrate otherwise disconnected lines of inquiry and, thereby, to contribute to advancing existing knowledge in the learning research field. It seems crucial to better understand the processes at work during mathematical problem-solving tasks in order to provide practitioners with the most adaptive solutions.

\section{Method}

\subsection{Participants}

A sample of 267 upper elementary students took part in the first part of the present study. They came from seven French-speaking Belgian schools located in different cities and had different socio-economic backgrounds and levels of performance. The "gradual-all together" group was made up of 86 students (M age $=10.8 ; \mathrm{SD}=0.89), 48.8 \%$ of which were girls; the "simultaneous" group consisted of 79 students $(\mathrm{M}$ age $=$ 10.5 ; $\mathrm{SD}=0.66$ ), of which 53.2\% were girls. With respect to the control group, it was composed of 102 students $(\mathrm{M}$ age $=10.7 ; \mathrm{SD}=0.87)$, of which $45.1 \%$ were girls. For the second part of the present study, only students with a "novice" or "expert" problem-solver profile, defined on the basis of their problem-solving performance at Time 1 (pretest), were sampled. Students with an average score below 0.5 out of 1 were called "novice" problem-solvers whereas those with an average score above or equal to 0.8 out of 1 were labelled "expert" problem-solvers. This selection was consistent with the teachers' assessments. In each group, 43 novice problem-solvers and 12 expert problem-solvers participated in this second study.

\subsection{Training program}

The two teaching approaches examined in the present study are based on a similar training program aiming at developing among students an expert and reflexive approach to problem solving (description available in Appendix A).

With respect to the two teaching approaches tested, as described above, they differed in how the heuristic strategies were taught. The "gradual-all together" approach consisted in teaching one heuristic at a time. In each problem, between one and two heuristics were addressed. It was only when all the heuristic strategies had been examined individually that the learner had to implement, within the same problem, the full set of heuristics, that is, to address them as interactive. Conversely, in the "simultaneous" approach, the heuristic strategies were all taught in the first problem while solving it. Then, for each subsequent problem, the student had to apply the full set of strategies in a flexible way. During the same period, with a similar frequency, the students in the control group worked on the statement of the same problems. However, unlike the teachers of the "gradual-all together" and of the "simultaneous" groups, the teachers of the control group received no methodological instructions. The problems were therefore handled according to the teacher's usual instructional practices for problem solving. 
The intervention extended over five weeks at the rate of two non-routine problems a week plus three weeks of pretest, post-test, and follow-up assessment (see Table 1). In addition, note that, for the sake of ecological validity, the training programs were implemented by the regular classroom teachers.

Table 1

Illustration of the research design.

\begin{tabular}{|c|c|c|c|}
\hline & "Gradual-all together" condition & "Simultaneous" condition & Control condition \\
\hline W1 & Pretest & Pretest & Pretest \\
\hline W2 & $\begin{array}{l}\text { How to make a representation and an } \\
\text { estimation }\end{array}$ & $\begin{array}{l}\text { Explicit teaching of the problem- } \\
\text { solving process (part 1) }\end{array}$ & Problem 1 \\
\hline W2 & Reinvestment in a new problem & $\begin{array}{l}\text { Explicit teaching of the problem- } \\
\text { solving process (part 2) }\end{array}$ & Problem 2 \\
\hline W3 & How to use one's knowledge & $\begin{array}{l}\text { Explicit teaching of the problem- } \\
\text { solving process (part 3) }\end{array}$ & Problem 3 \\
\hline W3 & Reinvestment in a new problem & $\begin{array}{l}\text { Explicit teaching of the problem- } \\
\text { solving process (part } 4 \text { ) }\end{array}$ & Problem 4 \\
\hline W4 & How to plan & $\begin{array}{l}\text { Reinvestment of the whole } \\
\text { process in a new problem }\end{array}$ & Problem 5 \\
\hline W4 & $\begin{array}{l}\text { Reinvestment in a new problem }+ \text { how } \\
\text { to check the calculations and the } \\
\text { procedure }\end{array}$ & $\begin{array}{l}\text { Reinvestment of the whole } \\
\text { process in a new problem }\end{array}$ & Problem 6 \\
\hline W5 & How to interpret and communicate & $\begin{array}{l}\text { Reinvestment of the whole } \\
\text { process in a new problem }\end{array}$ & Problem 7 \\
\hline W5 & $\begin{array}{l}\text { Reinvestment of the whole process in } \\
\text { a new problem }\end{array}$ & $\begin{array}{l}\text { Reinvestment of the whole } \\
\text { process in a new problem }\end{array}$ & Problem 8 \\
\hline W6 & $\begin{array}{l}\text { Reinvestment of the whole process in } \\
\text { a new problem }\end{array}$ & $\begin{array}{l}\text { Reinvestment of the whole } \\
\text { process in a new problem }\end{array}$ & Problem 9 \\
\hline W6 & $\begin{array}{l}\text { Reinvestment of the whole process in } \\
\text { a new problem }\end{array}$ & $\begin{array}{l}\text { Reinvestment of the whole } \\
\text { process in a new problem }\end{array}$ & Problem 10 \\
\hline W7 & Post-test & Post-test & Post-test \\
\hline W13 & Retention test & Retention test & Retention test \\
\hline
\end{tabular}

Note. $\mathrm{W} 1=$ week $1 ; \mathrm{W} 2=$ week 2 , etc.

As outlined by Durlak and Dupre (2008), one cannot interpret the results of the implementation of a training program without first ensuring that it has been delivered as planned. Therefore, the fidelity of implementation of the training program was evaluated. First, a check-list that contained step-by-step instructions was provided for each lesson. As the teacher completed a step, he or she had to check it off. Examination of the checklists showed that teachers completed $95 \%$ of the steps as prescribed. Second, teachers were asked to keep a diary with their feelings, students' responsiveness, potential amendments, and any other piece of information considered to be relevant. On this point, while the teachers reported being convinced of the relevance of the training program, they also pointed out that it was too intense. This observation was seen in particular from the teachers of the "simultaneous" group, who reported: "I think that what we did has had an impact, I mean I saw a change, changes in behavior, such as greater ease getting to work, greater autonomy, etc. But, we were very restricted in terms of time and thus I think that it did not leave them the time to digest the information because it was too fast, I think that it was the main problem. This must be done in the longer term". Third, the teachers received a half-day's training during which the components of the training program were outlined. A manual containing the description of the training program components and the lesson plans as well as detailed examples of anticipated correct representations, procedures and solutions was given 
to each teacher. Finally, meetings were organized to exchange positive experiences and difficulties encountered as well as to take stock of the past lessons and to plan those to follow.

\subsection{Measures}

First of all, it is important to point out that the three groups completed all of the measures presented below on three occasions: prior to the intervention, immediately after it, and then six weeks later.

Problem-solving performance was assessed by means of a performance test made up of three nonroutine problems. This test was designed on the basis of our expertise in mathematics teaching and on Fagnant and Demonty's (2005) textbook. The students' performance was appraised by a global score obtained by averaging their scores for the three items on a binary scale $(0=$ wrong answer, $1=$ right answer $)$. The test took on average 30 minutes to complete. It is noteworthy that for each measurement point, the same three mathematical structures were used to design the problem statements, and only the presentation of the problem was modified. In addition, students were asked to indicate all their reasoning and calculations on their sheet, not to erase anything, but to cross out if necessary.

Heuristic strategies were measured on the basis of students' written products. More precisely, we scrutinized their pre-test, post-test, and follow-up tests for traces of the application of five ${ }^{8}$ of the eight heuristic strategies taught, namely, building a representation, using one's knowledge, planning, checking the outcome and the procedure, and interpreting the outcome. A score for each heuristic strategy was computed according to a binary scale $(0=$ missing; $1=$ present $)$. Note that the presence of each heuristic strategy was measured and not the accuracy.

Persistence was appraised by means of an adapted and translated version of the "Attitude Toward Mathematics Survey" scale (Fredricks \& McColskey, 2012), one of the few existing instruments offering a persistence scale that is isolated from behavioral engagement. The adapted version measures persistence in mathematical problem solving through 8 items (e.g. "When I have trouble understanding a math problem, I reexamine it until I understand it") rated on a 4-point Likert scale $(1=($ almost $)$ never to $4=($ almost $)$ always $)$. The internal consistency of the global score was satisfactory to good (pretest: $\alpha=.65$, posttest: $\alpha=.87$, followup test: $\alpha=.81$ ).

The emotions experienced by the students while solving a mathematical problem were evaluated through a questionnaire presenting facial expressions. These latter included positive emotions (enjoyment, pride, relief), and negative emotions (boredom, fear, anger, hopelessness, shame, worry, frustration, and nervousness) most frequently experienced by elementary and secondary students when dealing with problemsolving tasks (Op't Eynde et al., 2004; Pekrun, Goetz, \& Frenzel, 2005). Students were asked to indicate to what extent they felt each emotion when solving a math problem using a 5-point Likert scale $(1=$ never to 5 $=$ always). The internal consistency of the global score for positive emotions (pretest: $\alpha=.78$, posttest: $\alpha=$ .74 , follow-up test: $\alpha=.74$ ) as well as that of the global score for negative emotions (pretest: $\alpha=.82$, posttest: $\alpha=.82$, follow-up test: $\alpha=.87$ ) was good.

Emotion regulation strategies were appraised using the Children's Emotion Regulation Scale in Mathematics (CERS-M) designed and validated by Hanin et al. (2017). This questionnaire has shown good psychometric properties with Belgian upper elementary students. It consists of 14 items, rated on a 4-point

\footnotetext{
${ }^{8} \mathrm{We}$ chose not to report the results pertaining to the estimation, execution of the calculations and communication strategies. First, students' estimations were very broad and vague, making the data unexploitable. Second, as shown in a previous study (Hanin, \& Van Nieuwenhoven, 2016), the execution of calculations and the communication strategies are used relatively frequently by students even before any intervention. These strategies did not therefore discriminate well between the three conditions.
} 
Likert scale (ranging from $1=($ almost $)$ never to $4=($ almost $)$ always $)$ and targets six strategies used by $5^{\text {th }}$ and $6^{\text {th }}$ graders to regulate their emotions when solving math problems, namely, task utility self-persuasion (e.g. "Even if I do not like solving math problems, I tell myself that it is important to do so in order to be able to understand them and thereby to succeed"), help-seeking (e.g. "I ask the teacher to help me to solve the problem"), brief attentional relaxation (e.g. "I put down my pencil for a few seconds and stretch my arms"), emotion expression (e.g. "I tell my neighbor that the problem makes me angry, sad, hopeless, or bored"), negative self-talk (e.g. "I tell myself that it is terrible not being able to solve the problem and that I am sure that it only happens to me"), and dysfunctional avoidance (e.g. "In order not to experience an unpleasant moment, I tell myself that I will solve the problem later"). The CERS-M subscales showed acceptable internal consistency for the three measurement times in the present sample with scale reliabilities ranging from .64 to .84 .

\subsection{Analysis}

To achieve our two research goals, three procedures were carried out. First, mixed-model group ("gradual-all together" vs. "simultaneous" vs. control) x Time (Time 1 vs. Time 2 vs. Time 3 ) repeated measures analyses of variance (ANOVAs) were performed on each measure, with time as the within-subject factor and group as the between-subjects factor. This gave us a general overview of the variables for which the three groups were distinguishable. Second, these first results were refined by examining, for all of the variables under consideration, short-term changes (between Time 1 and Time 2), long-term changes (between Time 1 and Time 3) and post-intervention changes (between Time 2 and Time 3). Repeated measures ANOVAs $^{9}$ were therefore performed. Third, for each of the variables presenting a significant short-term, longterm or post-intervention development, paired $t$-tests were performed in order to characterize the development of each group. We used the Bonferroni correction for the $t$-tests in order to avoid a potential alpha error inflation (Field, 2013). We report here the corrected p-values. In addition, in order to have a more accurate understanding of the effects, we reported the effect sizes. The latter were computed on the basis of Cumming's (2012) recommendations, that is, the calculation of Cohen's $d$ to which we applied a correction to remove the effect size's bias. Cohen's $d$ was calculated using the standard formula: $d_{u n b}=\left(1-\frac{3}{4 d f-1}\right) d$ with $d=$ $\frac{M_{\text {Pre }}-M_{\text {pos }}}{\frac{S_{\text {pre }}+S_{\text {pos }}}{2}}$.

\section{Results}

\subsection{Question 1: In terms of learning, would it be better to teach non-routine problem solving according} to a "simultaneous" approach or a "gradual-all together" approach?

In order to check for any baseline differences at pretest between the three groups, a univariate ANOVA was performed for the variables under consideration. The three groups differed regarding only the emotion expression strategy (see Appendix B).

\subsubsection{Overall effect of the problem-solving intervention}

Significant Group $\mathrm{x}$ Time interactions were found for persistence $(F(2,264)=4.244, p=$ .002 , partial $\left.\eta^{2}=.06\right)$. With respect to heuristic strategies, findings revealed significant Group $\mathrm{x}$ Time interactions for three out of the five strategies measured, namely, building a representation of the problem $\left(F(2,264)=25.778, p<.001\right.$, partial $\left.\eta^{2}=.19\right) ;$ using one's knowledge $(F(2,264)=12.971, p<$

\footnotetext{
${ }^{9} \mathrm{We}$ ensured beforehand that the assumptions were met for using ANOVA. These assumptions are the independence of the observations, the homogeneity of variance, the normality of residuals and the sphericity of the variance-covariance matrices (Field, 2013).
} 
.001 , partial $\left.\eta^{2}=.10\right)$ and planning $\left(F(2,264)=10.588, p<.001\right.$, partial $\left.\eta^{2}=.09\right)$. Regarding the emotion regulation strategies, two of them presented a significant Group x Time interaction, namely, helpseeking $\left(F(2,264)=3.643, p=.006\right.$, partial $\left.\eta^{2}=.04\right)$ and negative self-talk $(F(2,264)=2.747, p=$ .028 , partial $\left.\eta^{2}=.03\right)$. However, it is noteworthy that while the effect sizes are moderate to large for the heuristic strategies, they are quite small for the emotion regulation strategies.

\subsubsection{Short- and long-term effects and change dynamics}

With respect to short-term changes (between Time 1 and Time 2), the three groups differed for persistence; for three heuristic strategies, namely, building a representation of the problem, using one's knowledge and planning; and for two emotion regulation strategies, help-seeking (significant trend) and negative self-talk (see Appendix E).

A finer analysis showed that, contrary to our expectations, only the "simultaneous" group stood out regarding the persistence variable $(t(78)=-4.816, p<.001, d=.78)$ by displaying a significant increase. However, this finding must be put into perspective, given the relatively small effect size. With respect to heuristic strategies, the three groups presented a significant increase in the use of the strategy of building a representation of the problem. On this point, the "gradual-all together" group $(t(85)=-10.184, p<$ $.001, d=.1 .57)$ and the "simultaneous" group $(t(78)=-13.711, p<.001, d=2.09)$ displayed larger effect sizes as compared to the control group $(t(101)=-3.494, p=.003, d=.42)$. With regard to the planning strategy, both the "gradual-all together" group $(t(85)=-5.809, p<.001, d=.92)$ and the "simultaneous" group $(t(78)=-6.538, p<.001, d=1.02)$ displayed a significant improvement. The same results were observed regarding the strategy of "using one's knowledge", that is, there was a significant increase for both the "gradual-all together" group $(t(85)=-5.706, p<.001, d=.99)$ and the "simultaneous" group $(t(78)=-7.633, p<.001, d=1.21)$. As far as emotion regulation strategies are concerned, it turned out that the "simultaneous" group resorted less frequently to the help-seeking strategy at Time 2 than at Time $1(t(78)=3.155, p=.006, d=.40)$. Furthermore, while a significant Group $\mathrm{x}$ Time interaction was found regarding the negative self-talk strategy, fine-grained $t$-test analyses revealed that none of the three groups showed significant development.

With regard to long-term changes (between Time 1 and Time 3), four out of the six significant shortterm differences found at Time 2 compared with Time 1 were also significant over the longer term, at Time 3 (see Appendix E). Specifically, the same three heuristic strategies that showed short-term changes also presented significant increases at Time 3. The same behavior was observed for the three strategies, that is, a significant increase for both the "gradual-all together" group (building a representation of the problem: $t(85)=-7.671, p<.001, d=1.08$;

using one's knowledge: $t(85)=-5.023, p<.001, d=.81 ; \quad$ planning: $t(85)=-4.815, p<.001, d=$ .77 ) and the "simultaneous" group (Building a representation of the problem: $t(78)=-12.972, p<$ $.001, d=1.88$; using one's knowledge: $t(85)=-6.189, p<.001, d=.98 ; \quad$ planning: $t(85)=$ $-5.251, p<.001, d=.79$ ). Finally, with regard to emotion regulation strategies, results indicated a significant decrease in the use of the help-seeking strategy by both the "gradual-all together" group $(t(85)=3.341, p=.003, d=.40)$ and the "simultaneous" group $(t(78)=5.440, p<.001, d=.69)$. However, it is noteworthy that the effect sizes are rather small.

In order to capture solely what happened after the intervention and in doing so to distinguish clearly between short and long-term changes, the difference between Time 2 and Time 3 was investigated (see Appendix E). On this point, it appeared that the "gradual-all together" group made substantially less use of the heuristic strategy of building a representation $(t(85)=3.428, p=.003, d=.38)$. Nevertheless, the effect sizes are very tenuous. Finally, a significant decrease in the use of the emotion expression strategy by the "gradual-all together" group must also be noted $(t(85)=2.621, p=.033, d=.25)$. 


\subsubsection{Discussion}

Our first research question investigated whether it is better for learning to teach the problem-solving process in its full complexity, that is, to teach all of the problem-solving heuristic strategies within the same problem-solving task (the "simultaneous" approach), or to teach one heuristic strategy at a time and only after that to implement them simultaneously within the same task (the "gradual-all together" approach).

Findings suggest that solving two non-routine mathematical problems weekly without specific methodological instructions is already effective, as reflected in the control group's increased use between Time 1 and Time 2 of the 'building a representation of the problem' heuristic strategy. However, this change did not persist after the end of the training program (no significant difference between Time 1 and Time 3). In this respect, Hanin and Van Nieuwenhoven (2016) have shown that this heuristic is one of the few to be traditionally taught in math classrooms, which is confirmed by the descriptive statistics at Time 1 (see Appendix B). Consequently, this strategy is not new for the students; they have already practiced it. On this point, scholars have shown that repeated practice and confrontation with the learning material promote knowledge and skills assimilation and internalization (Anderson, 1981; Piaget, 1978). Thus, when students become familiar with the representation heuristic strategy, which occurs faster thanks to previous practice, they may no longer feel the need to write their representation down and may prefer to do it mentally.

Teaching problem solving according to a "gradual-all together" approach appeared to be more effective at the cognitive, metacognitive and emotional levels than the traditional approach. At the cognitive level, results highlighted a short-term significant increase in the use of three heuristic strategies, namely, building a representation of the problem, using one's knowledge, and planning. While the improvement in the two last strategies persisted over time, a decrease in the use of the 'building a representation of the problem' heuristic strategy was recorded between Time 2 and Time 3. This observation supports the familiarizationinternalization assumption put forward earlier. In effect, through the training program proposed, not only did students have the opportunity to implement this strategy many times, they also received information about how to implement it, when it is the most convenient strategy, and what it is used for (the WWW \& H rule; Veenman, Van Hout-Wolters, \& Afflerbach, 2006). This method of instruction is known to promote students' understanding and familiarization with the learning material (Tzohar-Rozen \& Kramarski, 2017; Veenman et al., 2006). As a result, we may wonder why the other two strategies, namely, using one's knowledge and planning, were not also internalized by the students. In this regard, let us mention that the 'building a representation of the problem' strategy is relevant for each problem. Therefore, students had implemented it on many occasions. Moreover, descriptive statistics at Time 1 (see Appendix B) showed that of the three heuristic strategies, 'building a representation of the problem' was the only one that had really been exploited in the traditional classrooms before the beginning of the training program. Consequently, students had had more opportunities to practice it. Conversely, the planning strategy will not be invoked if the problem requires only one or two stage(s) to be solved. With respect to the 'using one's knowledge' strategy, as claimed by Fuchs et al. (2003), this will be fully used only at the point when the learner has encountered problems presenting different mathematical structures, has had the opportunity to identify these structures and has attempted these types of problems several times in order to build a typology of the problems' mathematical structures. At this stage, it is thus more the premises of the strategy that are observed. At the emotional level, the help-seeking strategy appeared to be used to a lesser extent in the long run by the students in the "gradualall together" group. Such a finding would suggest that the "gradual-all together" approach, through appropriate tooling and scaffolding, fostered among students a more responsible and autonomous approach to problem solving, in other words, a self-regulated approach. In effect, in such an approach, students rely less on their teacher and peers (help-seeking strategy) (Allal, 2007). Nonetheless, contrary to our supposition, the "gradualall together" approach did not enhance students' level of persistence.

The "simultaneous" approach to problem solving stood out as beneficial not only in terms of the cognitive and metacognitive aspects but also at the emotional and motivational levels. In effect, a short-term increase in the use of three heuristic strategies, namely, building a representation of the problem, using one's knowledge, and planning, as well as maintenance over time of the level reached were observed among the students of the "simultaneous" group. Thus, unlike their counterparts in both the control and the "gradual-all 
together" groups, the students in the "simultaneous" group seemed to still need to write down their representation of the problem at Time 3. This observation, although surprising at first sight, does not invalidate the familiarization-internalization hypothesis. As reported by the teachers, the intensity of the training program, especially in its "simultaneous" version, may not have given students the opportunity to assimilate and internalize entirely the heuristic strategies taught. In this respect, several scholars have pointed out that the duration, the intensity and the frequency of the intervention's activities impact the findings (Durlak, Weissberg, Dymnicki, Taylor, \& Schellinger, 2011; Greenberg, Domitrovich, Graczyk, \& Zins, 2005). In addition, the teaching approach itself may, in a complementary way, explain this observation. In the "simultaneous" approach, students' awareness was raised to deal with the various heuristic strategies in a coordinated way. More precisely, in this approach the representation strategy is viewed as a step determining all the others, that is, the step on which the subsequent heuristic strategies are built. Consequently, writing down one's representation may facilitate the continuation of the problem-solving process. In addition, a shortterm decrease in the use of the help-seeking strategy as well as a maintenance over time of this lower level were observed among the "simultaneous" group. Contrary to the "gradual-all together" group, for which the decrease appeared only at Time 3, in the "simultaneous" group, the same decrease was already observed at Time 2. So, contrary to our supposition, approaching the problem-solving process in its full complexity is more beneficial than a step-by-step approach. In other words, it is not enough to equip the learner adequately; the problem-solving approach must make sense for him/her. In this respect, not only did the "simultaneous" approach lead to faster changes in the development of self-regulated behaviors as compared to the "gradualall together" approach, it was also associated with a short-term increase in persistence. This finding suggests that students are able to handle and to overcome the difficulties encountered, which in turn supports the hypothesis that the "simultaneous" approach contributes to the development of self-regulated behaviors.

It follows from this first investigation that the "simultaneous" approach stands out as the most promising one in that it impacts the cognitive, metacognitive, emotional and motivational dimensions of problem-solving learning. However, is the "simultaneous" approach to problem solving appropriate for all profiles of students?

\subsection{Question 2: Is it appropriate to adopt a different teaching approach according to the learner's level of expertise in problem solving?}

Findings regarding novice problem-solvers are presented first, followed by those for expert learners.

Let us mention in advance that there were no baseline differences between the three groups of novice problem-solvers (see Appendix C).

\subsubsection{Overall effect of the problem-solving intervention on novices}

Significant Group x Time interactions were found for three heuristic strategies, namely, building a representation of the problem $\left(F(2,126)=12.830, p<.001\right.$, partial $\left.\eta^{2}=.18\right)$, using one's knowledge $\left(F(2,126)=4.651, p=.001\right.$, partial $\left.\eta^{2}=.07\right)$, and planning $\left(F(2,126)=5.054, p=.001\right.$, partial $\eta^{2}=$ $.08)$. Additionally, significant interactions were also found regarding two emotion regulation strategies, namely, help-seeking $\left(F(2,126)=4.949, p=.001\right.$, partial $\left.\eta^{2}=.09\right)$ and negative self-talk $(F(2,126)=$ $3.484, p=.009$, partial $\left.\eta^{2}=.06\right)$. Finally, the persistence dimension also showed a significant interaction $\left(F(2,126)=3.294, p=.013\right.$, partial $\left.\eta^{2}=.09\right)$.

\subsubsection{Short- and long-term effects and change dynamics regarding novices}

Regarding short-term changes, the three groups of novice problem-solvers differed in terms of three heuristic strategies (building a representation of the problem, using one's knowledge, and planning). In addition, the three groups were also distinguishable on three emotion regulation strategies (that is, task utility self-persuasion, help-seeking, negative self-talk) as well as on persistence (see Appendix F). 
In-depth analyses highlighted a substantial improvement for the three heuristic strategies presenting a significant increase, for both the "gradual-all together" group (building a representation of the problem: $t(42)=-6.525, p<.001, d=1.36$; $\quad$ using $\quad$ one's knowledge: $t(42)=-3.925, p<.001, d=$ 98; planning: $t(42)=-4.702, p<.001, d=1.17)$ and the "simultaneous" group $(t(42)=-10.898, p<$ $.001, d=2.31 ; t(42)=-4.611, p<.001, d=.99 ; t(42)=-4.370, p<.001, d=.94$; respectively).

As regards emotion regulation, a significant decrease in the use of the help-seeking strategy was recorded among the "simultaneous" group $(t(42)=3.204, p=.009, d=.59)$. Unexpectedly, the control group displayed a significant decrease in the use of the negative self-talk strategy $(t(42)=2.727, p=.030, d=$ .44). However, the magnitudes of the effects regarding emotion regulation strategies are rather weak. In addition, note that although repeated measures ANOVAs indicated a significant interaction regarding the task utility self-persuasion strategy, a finer-grained examination by means of $t$-tests showed that none of the three groups presented a significant development on this dimension. Finally, and contrary to our expectations, only the "simultaneous" group displayed a significant rise in persistence $(t(42)=-4.026, p=.003, d=.98)$.

With regard to long-term changes, four out of the six significant differences found at Time 2 compared with Time 1 were also significant at Time 3 (see Appendix F). First, the two experimental groups displayed a significant improvement regarding the use of heuristic strategies. More precisely, both the "gradual-all together" group $(t(42)=-6.561, p<.001, d=1.14 ; t(42)=-3.415, p=.003, d=$ $.74 ; t(42)=-4.760, p<.001, d=1.10$; respectively) and the "simultaneous" group $(t(42)=$ $-8.545, p<.001, d=1.70 ; t(42)=-4.128, p<.001, d=.86 ; t(42)=-3.553, p=.003, d=$

.71 ; respectively) displayed a significant improvement in the use of three heuristic strategies, namely, building a representation of the problem, using one's knowledge, and planning. In addition, regarding emotion regulation strategies, the "simultaneous" group used the help-seeking strategy much less $(t(42)=5.509, p<$ $.001, d=.88)$.

With respect to what happened after the intervention, although repeated measures ANOVAs indicated significant Group x Time interactions regarding persistence and the negative self-talk strategy, a finer-grained examination via $t$-tests revealed that there were no significant differences between Time 2 and Time 3, for any of the three groups.

Regarding expert problem-solvers, there were no baseline differences between the three groups except for the emotion expression strategy (see Appendix D).

\subsubsection{Overall effect of the problem-solving intervention regarding experts}

Significant Group $\mathrm{x}$ Time interactions were found for two heuristic strategies, namely, building a representation of the problem $\left(F(33,2)=5.072, p=.002\right.$, partial $\left.\eta^{2}=.28\right)$, and planning $(F(33,2)=$ $3.026, p=.026$, partial $\left.\eta^{2}=.19\right)$. Note that interactions with a significant trend were observed for both the strategy of using one's knowledge $\left(F(33,2)=2.533, p=.051^{t}\right.$, partial $\left.\eta^{2}=.16\right)$ and persistence $\left(F(33,2)=2.841, p=.07\right.$, partial $\left.\eta^{2}=.49\right)$.

\subsubsection{Short- and long-term effects and change dynamics regarding experts}

As regards short-term changes, the three groups of expert problem-solvers differed on the same cognitive and motivational variables as the novice problem-solvers, that is, persistence, building a representation of the problem, using one's knowledge and planning (see Appendix G). However, unlike novices, the three groups of expert learners were not distinguishable on the emotional dimension.

Both the "gradual-all together" group $(t(11)=-10.757, p<.001, d=3.96)$ and the "simultaneous" group $(t(11)=-6.280, p<.001, d=2,47)$ displayed a significant improvement in regard to the heuristic strategy of building a representation of the problem. The same findings were found regarding the strategy of using one's knowledge ("gradual-all together" group: $t(11)=-3.985, p=.009, d=1.66$; "simultaneous" group: $t(11)=-5.063, p<.001, d=1.92$ ). With respect to the planning strategy, a substantial 
improvement was observed within the "simultaneous" group $(t(11)=-4.710, p=.001, d=2.03)$. In addition, a significant improvement in persistence was recorded among the "simultaneous" group $(t(11)=-4.977, p=.048, d=1.84)$.

With respect to long-term changes, the four significant differences found at Time 2 compared with Time 1 were still significant at Time 3 (see Appendix G). As regards the heuristic strategies, both the "gradualall together" group and the "simultaneous" group used the same three strategies significantly more: building a representation of the problem ("gradual-all together" group: $\mathrm{t}(11)=-4.183, p=.006, d=$ 1.83; "simultaneous" group : $\mathrm{t}(11)=-8.848, p<.001, d=2.99), \quad$ using one's knowledge ("gradual-all together" group: $\mathrm{t}(11)=-3.40, p=.021, d=1.35$;"simultaneous" $g$ roup : $\mathrm{t}(11)=$ $-3.644, p=.012, d=1.38$ ) and planning ("gradual-all together" group: $\mathrm{t}(11)=-3.191, p=.027, d=$ 1.12; "simultaneous" group : $\mathrm{t}(11)=-2.809, p=.048, d=1.38)$. Finally, a significant increase in persistence was observed among the "simultaneous" group $(t(11)=-4.314, p=.006, d=.74)$.

\subsubsection{Discussion}

Our second research question examined whether it is productive for the teacher to adopt a different teaching approach ("gradual-all together" vs "simultaneous") according to the learner's level of expertise in non-routine problem solving.

Contrary to what we expected, our findings revealed that while the "gradual-all together" approach and the "simultaneous" approach are equally beneficial regarding the cognitive and metacognitive dimensions, the second approach is more effective with regard to the emotional and motivational aspects of problemsolving learning, regardless of the student's profile.

First, with respect to the cognitive dimension, novice and expert problem-solvers in both approaches displayed a significant increase and maintenance over time of the level reached for three heuristic strategies (building a representation of the problem, using one's knowledge, and planning). However, only these three heuristic strategies showed this positive development. Several assumptions may be put forward to explain why the heuristic strategies of "checking the outcome(s) and the procedure" and "interpreting the outcome" did not experience greater impact by the intervention. With respect to the former, checking is both time-consuming and cognitive resource-consuming in that the student must repeat calculations (outcome checking) and read over his work (procedure checking). The "interpreting the outcome" heuristic strategy, according to the descriptive statistics, presented a steady but not significant increase between the three times of measurement. This slower growth may be partially explained by teachers' beliefs. Nowadays it is widely acknowledged that teachers' beliefs influence their teaching (Beswick, 2006; Van Der Sandt, 2007; Wilkins, 2008). In this respect, several scholars have shown that a substantial proportion of teachers, when confronted with non-routine problems for which a realistic answer is expected, display a strong tendency to exclude realistic considerations; in other words, they believe that realistic considerations have no place in math classrooms (Depaepe et al., 2010). On this basis, we hypothesize that if, before presentation of the problem-solving process to the teachers, we had carried out a critical analysis of their misconceptions, the heuristic strategy of "interpreting the outcome" would have been used significantly more by their students. However, the positive growth in the use of this heuristic strategy within the three groups suggests that the nature of the problems proposed (requiring students to make sense of the outcome), had already brought about a change, although a slower one than if the problems had been preceded by an analysis. In a complementary way, these two strategies of checking and interpreting are located at the end of the problem-solving process. In this respect, teachers of both the "simultaneous" and the "gradual-all together" groups reported that the training program schedule was very intense, leaving little time for students to master each of the heuristic strategies. Consequently, it is possible that the last heuristic strategies were less developed.

Second, as for emotion regulation strategies, only novice learners experienced significant changes. On this point, it appeared that novices in the "simultaneous" group made less use of the help-seeking strategy. This finding suggests that, as previously mentioned, the "simultaneous" approach supports the development of more autonomous management of the problem-solving process. Moreover, a short-term significant decrease 
in the use of the "negative self-talk" strategy was observed among the novices in the control group. However, this decrease did not last over time. If this observation may sound a little surprising at first sight, as previously mentioned, scholars have shown that the repeated practice of an activity or of a set of knowledge improves the learner' skills and performance (Anderson, 1981; Fayol, 2006) and, as a result, diminishes anxiety and emotional internalization behaviors (Hampel, Meier, \& Kümmel, 2008; Kanfer, Ackerman, \& Heggestad, 1996). Thus, the simple weekly processing of two mathematical problems seems enough to reduce significantly the internalization of negative emotions. In our view, the intensity of both the "simultaneous" and the "gradual-all together" approaches may explain why such a decrease was not significant for these two approaches. Further, we hypothesize that the short duration of the intervention accounts for the nonmaintenance over time of the decrease in "negative self-talk" observed within the control group.

Third, concerning the motivational dimension, a short-term significant increase in persistence was observed among both novice and expert "simultaneous" learners. Although this improvement faded after the end of the training program for the former, it persisted over time for the latter. This finding may be explained by both the intensity and the short duration of the training program. More vulnerable students, such as novice problem-solvers, may not have had sufficient time to deeply assimilate the heuristic strategies taught. Consequently, at the end of the training program, they may not have felt better equipped to solve mathematical problems and their persistence fell back to its baseline level. Additionally, the lack of challenge or, at least, the low level of challenge involved in the "gradual-all together" approach may account for the stability of the persistence level observed among both novice and expert problem-solvers experiencing this approach. In this connection, a study conducted among seventh grade students underscored a positive and quite strong relationship between persistence in problem-solving tasks and a taste for challenging tasks (Malmivuori, 2006). Similarly, Wolters and Rosenthal (2000) showed that enhancing eighth grade students' interest in working on a task by making it more challenging or meaningful increased their persistence for the task.

In short, consistent with the work done on mathematics instruction, it is clear that a training program that approaches problem solving in its full complexity, and thereby puts the focus on an understanding of the process, is cognitively, metacognitively, motivationally and emotionally more fruitful for both the novice and the expert problem-solver than the "gradual-all together" approach.

\section{General discussion and conclusion}

For decades, problem solving has constituted a real stumbling block both for students and for teachers who report having difficulty helping their students with this type of task (Fagnant, Dupont, \& Demonty, 2016). While many scholars have developed training programs that aim to develop an expert and reflexive approach to problem solving among elementary and secondary students, they have recommended different teaching approaches without identifying the most effective one (Blum, 2011; De Corte et al., 2004; Fagnant \& Demonty, 2005; Tzohar-Rozen \& Kramarski, 2017). Yet, in order to improve the teaching of non-routine problem solving and so improve students' problem-solving learning and performance, it is important to compare the effectiveness of these various approaches. The present paper contributes to advancing the existing knowledge about problem-solving instruction by examining whether it is more fruitful to teach the problem-solving process in all its complexity (the "simultaneous" approach) or one heuristic strategy at a time ("the gradual-all together" approach).

First, our findings highlight that, while both learning approaches support the acquisition of cognitive strategies over the short- and the long-term, if student motivation and a positive emotional rapport with problem-solving tasks are taken into account, the "simultaneous" approach, and thus, the maintenance of complexity, is more beneficial, for both novice and expert students. In this sense, our results support the work done in mathematics instruction that stresses the importance of proposing realistic, meaningful, challenging and complex problem-solving tasks. As these findings contradict current classroom practices, they are of 
particular importance. On this point, research has shown that in order to facilitate task completion for their students, teachers reduce complex tasks to micro-tasks, especially for students with a "novice" profile (Demonty \& Fagnant, 2014; Depaepe et al., 2010). These micro-tasks require students to apply procedures that are meaningless for the task requested. For example, the task of making a representation of a problem does not make sense per se, unless the student then goes on to solve the problem afterward. So, this study draws attention to the fact that the difficulties experienced by students in problem solving have more to do with the inadequacy of the tasks proposed to prepare them for managing complexity than with the manage ment of the complexity itself. Concretely, it emphasized that, for a novice to become proficient at solving complex tasks, such as mathematical problems, requires repeated confrontation with such tasks. In this respect, Ericsson's theory of deliberate practice (Ericsson, 2008; Ericsson, Krampe, \& Tesch-Römer, 1993) has shown, through several empirical studies, that considerable practice, in the sense of the number of hours devoted to the practice of the competence that one wishes to acquire, is a prerequisite for the automation of such competence. A practical spin-off would be to increase the practice of solving complex tasks in classes. A second contribution of our study to advancing existing knowledge regards heuristic strategies. It follows from our results that the strategies taught are not acquired at the same pace by the learner. Some strategies, less familiar, based on inadequate belief or requiring more cognitive resources, take longer to be integrated. This information is critical for designing more effective training programs, as each strategy occupies a specific and central place in the problem-solving process. A study conducted with students of the same age emphasized that to increase more rapidly students' use of the "checking" and the "interpreting" strategies, it is necessary to add emotional and motivational support to the cognitive and metacognitive intervention (Hanin, \& Van Nieuwenhoven, 2018b). This observation is in line with self-regulated learning theories, which postulate that motivational beliefs and emotions play a key role not only in initiating the learning process but also in sustaining the learner's efforts throughout the process (Boekaerts, 2011; Zimmerman, 2011). A third contribution pertains to the emotional aspects of problem-solving tasks. Our findings reveal that differences regarding emotional variables between the three groups are quite limited. This study highlights that nurturing one aspect of selfregulation (in the present case, the cognitive one) has little effect on the other ones (here the emotional aspect). So, it would seem that to induce emotional regulation among learners, it is necessary to explicitly teach emotional knowledge and skills. This echoes and supports a recent exploratory study conducted among fifth graders by Tzohar-Rozen and Kramarski (2017). In this way, the present study adds nuance to the empirical studies conducted so far, which have shown that learners who receive metacognitive support for problemsolving tasks display greater general motivation as well (Hoffman, 2010; Kramarski \& Gutman, 2006). This means, from a conceptual point of view, that if the processes involved in the regulation of cognition share common points with those involved in the regulation of motivation, they are distinct from those entangled in the regulation of emotions. This observation makes it possible to refine and add nuance to current literature on the subject. Fourth and last, we used an original method that consists in establishing a dialogue between two research fields that deal with similar issues but that are not usually involved in an interdisciplinary context with the purpose of advancing existing knowledge about problem solving and allowing new empirical insights. Priolet (2014) talked about an "integrative theoretical framework" to designate "the mobilization of works related to mathematics instruction and to both the psychology of learning and of development" (p. 60, our translation). More precisely, in addition to being based on an instructional analysis, our findings underline the necessity of presenting to students teaching-learning situations that take into account their cognitive, emotional and motivational functioning and the contextual features in which the learning takes place in order to be truly functional (Maury, 2001; Priolet, 2014). The present study confirms that we cannot offer students a training program that has "just" been thought of "mathematically". So, not only does adopting such an integrative perspective allow for better understanding of the processes at work during mathematical problem-solving tasks and thereby for drawing firmer conclusions for practical guidance, but it is also essential for understanding problem-solving competence in all its complexity.

In addition, this study draws attention not only to the importance of providing learning activities that make sense to the learner but also to the difference between "the learner's academic fulfillment" and "the learner's academic performance". In other words, our findings suggest that developing students' heuristic strategies, emotion regulation strategies and motivation, on the one hand, and increasing his/her performance on the other, are not always compatible processes. The weight placed by our politicians on both national and 
international tests is a good reflection of current concerns. However, the perennial low success rates, mentioned in the introduction, suggest that this may not be a very productive avenue. Maybe it is time to ask whether schools should be more concerned about educating "achievers" or long-term, engaged learners.

While the present study yields promising results for both the educational and research perspectives, several limitations that call for further investigations must be noted. First, several changes did not persist, took place quite slowly or were fairly weak. This suggests the need for a training program that is less intense (where the lessons are more spaced out in time), of longer duration (where the learner has more opportunities to implement what he/she has learned in new problem situations) and that directly addresses the emotional dimension (by including lessons on emotions and emotion regulation strategies). Such a training program might lead to better uptake of all the heuristic strategies taught, to better emotional regulation, and consequently to better performance. Second, as this is, to our knowledge, the first study to investigate these questions at the level of compulsory education, it would be interesting to replicate it with other samples in order to strengthen the stability of the present findings, especially as it partially questions the assumptions of cognitive load theory. Third, as previously mentioned, the study would benefit from a more fine-grained measure of the heuristic strategies. On this point, in order to have a better understanding of the link between the heuristic strategies and the performance score, adding a measure of the accuracy of the implementation of each heuristic strategy would be enlightening. Fourth, in the present study expert and novice solvers were assigned in terms of high and low performance, as is the case in many studies of novice and expert learners (Bassok 2003; Brand et al., 2003; Muir et al., 2008). However, defining expertise in problem solving exclusively in terms of performance is restrictive. Consequently, it would be interesting in future studies to more thoroughly conceptualize these two learner profiles. Fifth and last, it is noteworthy that the results regarding the expert problem-solvers depend on the sample size. This was rather small, which makes it necessary to replicate the present study with a bigger sample of expert problem-solvers.

\section{Disclosure of interest}

The authors declare that they have no conflicts of interest concerning this article and approve the final article.

\section{Keypoints}

Examines two contrasting approaches to teaching the problem-solving process;

Shows that both approaches support the acquisition of cognitive strategies;

Identifies meaningfulness of approach as key for emotional and motivational benefits to occur;

Highlights the fact that the emotional dimension concerns only novice problem-solvers;

Makes it possible to design more targeted and more efficient pedagogical interventions.

\section{References}

Ahmed, W., van der Werf, G., Kuyper, H., \& Minnaert, A. (2013). Emotions, self-regulated learning, and achievement in mathematics: a growth curve analysis. Journal of Educational Psychology, 105(1), 150-161. doi :10.1037/a0030160.

Allal, L. (2007). Régulations des apprentissages: orientations conceptuelles pour la recherche et la pratique en éducation [Regulation of learning: conceptual guidelines for research and practice in education]. In L. Allal \& L. Mottier Lopez (Eds.), Régulation des apprentissages en situation scolaire et en formation [Regulation of learning in educational and instructional situations] (pp. 7-24). Brussels: De Boeck.

Anderson, J. R. (1981). Cognitive skills and their acquisition. Hillsdale, NJ: Lawrence Erlbaum Associates. 
Bassok, M. (2003). Analogical transfer in problem solving. In J. E. Davidson \& R. J. Sternberg (Eds.), The psychology of problem solving (pp. 343-369). New York, NY: Cambridge University Press.

Beswick, K. (2006). The importance of mathematics teachers' beliefs. The Australian Mathematics Teacher, 62(4), 17-22.

Blayney, P., Kalyuga, S., \& Sweller, J. (2010). Interactions between the isolated-interactive elements effect and levels of learner expertise: experimental evidence from an accountancy class. Instructional Science, 38(3), 277-287. doi: 10.1007/s11251-009-9105-x.

Blum, W. (2011). Can modelling be taught and learnt? Some answers from empirical research. In G. Kaiser, W. Blum, R. Borromeo Ferri, \& G. Stillman (Eds.), Trends in teaching and learning mathematical modelling (pp. 15-30). New York, NY: Springer.

Blum, W., \& Niss, M. (1991). Applied mathematical problem solving, modelling, applications, and links to other subjects. State, trends and issues in mathematics instruction. Educational Studies in Mathematics, 22(1), 37-68. doi: 10.1007/BF00302716.

Boekaerts, M. (2011). Emotions, emotion regulation, and self-regulation of learning. In B. J. Zimmerman \& D. H. Schunk (Eds.), Handbook of self-regulation of learning and performance (pp. 408-425). New York, NY: Routledge.

Brand, S., Reimer, T., \& Opwis, K. (2003). Effects of metacognitive thinking and knowledge acquisition in dyads on individual problem solving and transfer performance. Swiss Journal of Psychology, 62(4), 251-261. doi: 10.1024/1421-0185.62.4.251.

Brault-Labbé, A., \& Dubé, L. (2008). Engagement, surengagement et sous-engagement académiques au collégial: pour mieux comprendre le bien-être des étudiants [Academic commitment, overcommitment and under-commitment at secondary school: understanding students' wellbeing]. Revue des sciences de l'éducation, 34(3), 729-751. doi: 10.7202/029516ar.

Cumming, G. (2012). Understanding the new statistics. Effect sizes, confidence, intervals, and meta-analysis. New York, NY: Routledge.

De Corte, E. (2012). Constructive, self-regulated, situated and collaborative (CSSC) learning: an approach for the acquisition of adaptive competence. Journal of Education, 192(2/3), 33-47.

De Corte, E., Depaepe, F., Op't Eynde, P., \& Verschaffel, L. (2011). Students' self-regulation of emotions in mathematics: an analysis of meta-emotional knowledge and skills. ZDM, 43(4), 483-495.

De Corte, E., Verschaffel, L., \& Masui, C. (2004). The CLIA-model: a framework for designing powerful learning environments for thinking and problem solving. European Journal of Psychology of Education, 19(4), 365-384.

Demonty, I., Blondin, C., Matoul, A., Baye, A., \& Lafontaine, D. (2013). La culture mathématique à 15 ans. Premiers résultats de Pisa 2012 en Fédération Wallonie-Bruxelles [Mathematical knowledge at 15 years old. First results of Pisa 2012 in the Wallonia-Brussels Federation]. Les Cahiers des Sciences de l'Education, 34, 1-26.

Demonty, I., \& Fagnant, A. (2014). Tâches complexes en mathématiques : difficultés des élèves et exploitations collectives en classe [Complex mathematical tasks: students' difficulties and whole-class practice]. Education et Francophonie, 42(2), 173-189. doi : 10.7202/1027912ar.

Depaepe, F., De Corte, E., \& Verschaffel, L. (2010). Teachers' approaches towards word problem solving: elaborating or restricting the problem context. Teaching and Teacher Education, 26(2), 152-160. doi: 10.1016/j.tate.2009.03.016.

Durlak, J. A., \& DuPre, E. P. (2008). Implementation matters: a review of research on the influence of implementation on program outcomes and the factors affecting implementation. American Journal of Community Psychology, 41(3-4), 327-350. doi : 10.1007/s10464-008-9165-0.

Durlak, J. A., Weissberg, R. P., Dymnicki, A. B., Taylor, R. D., \& Schellinger, K. B. (2011). The impact of enhancing students' social and emotional learning: A meta-analysis of school-based universal interventions. Child Development, 82(1), 405-432. doi: 10.1111/j.1467-8624.2010.01564.x.

Elia, I., van den Heuvel-Panhuizen, M., \& Kolovou, A. (2009). Exploring strategy use and strategy flexibility in non-routine problem solving by primary school high achievers in mathematics, ZDM Mathematics Education, 41(5), 605-618.

Ericsson, K. A. (2008). Deliberate practice and acquisition of expert performance: a general overview. Academic Emergency Medicine, 15, 988-994. 
Ericsson, K. A., Krampe, R. T., \& Tesch-Römer, C. (1993). The role of deliberate practice in the acquisition of expert performance. Psychological Review, 100, 363-406.

Fagnant, A., \& Demonty, I. (2005). Résoudre des problèmes : pas de problème! Guide méthodologique et documents reproductibles. 10/12 ans [Solving problems: no problem! Methodological guide and reproducible documents. 10/12 years]. Brussels : De Boeck.

Fagnant, A., Demonty, I., \& Lejonc, M. (2003). La résolution de problèmes: un processus complexe de « modélisation mathématique » [Problem-solving: a complex process of "mathematical modeling"]. Bulletin d'informations pédagogiques, 54, 29-39.

Fagnant, A., Dupont, V., \& Demonty, I. (2016). Régulation interactive et résolution de tâches complexes en mathématiques [Interactive regulation and complex tasks in mathematics]. In L. Mottier Lopez \& W. Tessaro (Eds.), Le jugement professionnel au cœur de l'évaluation et de la régulation des apprentissages [Professional judgment at the core of evaluation and regulation of learning] (pp. 229251 ). Berne: Peter Lang.

Fagnant, A., \& Jaegers, D. (2018). Soutenir l'autorégulation cognitive et développer les compétences en résolution de problèmes: une étude exploratoire en fin d'enseignement primaire [Supporting cognitive self-regulation and developing problem-solving skills: an exploratory study at the end of primary education]. In S. Cartier \& L. Mottier Lopez (Eds.), Soutien à l'apprentissage autorégulé en contexte scolaire: perspectives francophones [Support for self-regulated learning in the school context: francophone perspectives] (pp. 161-181). Quebec: Presses de l'Université du Québec.

Fayol, M. (2006). Un esprit pour apprendre [A mind to learn]. In E. Bourgeois \& G. Chapelle (Eds.), Apprendre et faire apprendre [To learn and to teach] (pp.53-67). Paris: PUF.

Field, A. (2013). Discovering statistics using IBM SPSS statistics (4th ed.). London: SAGE Publications.

Fredricks, J. A., \& McColskey, W. (2012). The measurement of student engagement: a comparative analysis of various methods and student self-report instruments. In S. L. Christenson, A. L. Reschly, \& C. Wylie (Eds.), Handbook of research on student engagement (pp. 763-782). New York, NY: Springer US.

Fuchs, L. S., Fuchs, D., Prentice, K., Burch, M., Hamlett, C. L., et al. (2003). Explicitly teaching for transfer: Effects on third-grade students' mathematical problem solving. Journal of Educational Psychology, 95(2), 293-305.

Greenberg, M. T., Domitrovich, C. E., Graczyk, P. A., \& Zins, J. E. (2005). The study of implementation in school-based preventive interventions: theory, research, and practice. Washington, DC: Center for Mental Health Services, Substance Abuse and Mental Health Administration, U.S. Department of Health and Human Services.

Hampel, P., Meier, M., \& Kümmel, U. (2008). School-based stress management training for adolescents: longitudinal results from an experimental study. Journal of Youth and Adolescence, 37(8), 1009-1024. doi: 10.1007/s10964-007-9204-4.

Hanin, V., \& Van Nieuwenhoven, C. (2016). Evaluation d'un dispositif pédagogique visant le développement de strategies cognitives et métacognitives en résolution de problème en première secondaire [Evaluation of a training-program aiming at the development of cognitive and metacognitive strategies in problem-solving among grade one students]. E-Jiref, 2(1), 53-88.

Hanin, V., Grégoire, J., Mikolajczak, M., Fantini-Hauwel \& Van Nieuwenhoven, C. (2017). Children's Emotion Regulation Scale in Mathematics (CERS-M): development and validation of a self-reported instrument. Psychology, 8(13), 2240-2275. doi : 10.4236/psych.2017.813143.

Hanin, V., \& Van Nieuwenhoven, C. (2018a). Evaluation d'un dispositif d'enseignement apprentissage en resolution de problèmes mathématiques: Evolution des comportements cognitifs, métacognitifs, motivationnels et émotionnels d'un résolveur novice et expert [Evaluation of a training-program in mathematical problem-solving: Evolution of cognitive, metacognitive, motivational and emotional behaviors of an expert and a novice solver]. E-Jiref, 4(1), 37-66.

Hanin, V., \& Van Nieuwenhoven, C. (2018b). Developing an expert and reflexive approach to problemsolving: the place of emotional knowledge and skills. Psychology, 9(2), 280-309. doi: 10.4236/psych.2018.92018. 
Hoffman, B. (2010). I think I can, but I'm afraid to try: The influence of self-efficacy and anxiety on problemsolving efficiency. Learning \& Individual Differences, 20, 276-283.

Kanfer, R., Ackerman, P. L., \& Heggestad, E. D. (1996). Motivational skills \& self-regulation for learning: a trait perspective. Learning and Individual Differences, 8(3), 185-209. doi: 10.1016/S10416080(96)90014-X.

Kramarski, B., \& Gutman, M. (2006). How can self-regulated learning be supported in mathematical Elearning environments? Journal of Computer Assisted Learning, 22(1), 24-33.

Lucangeli, D., Tressoldi, P. E., \& Cendron, M. (1998). Cognitive and metacognitive abilities involved in the solution of mathematical word problems: Validation of a comprehensive model. Contemporary Educational Psychology, 23(3), 257-275.

Malmivuori, M. L. (2006). Affect and self-regulation. Educational Studies in Mathematics, 63(2), 149-164. doi: 10.1007/s10649-006-9022-8.

Maury, S. (2001). Didactique des mathématiques et psychologie cognitive : un regard comparatif sur trois approches psychologiques [Didactics of mathematics and cognitive psychology: a comparative look at three psychological approaches]. Revue française de pédagogie, 137, 84-89.

Montague, M., \& Applegate. (2000). Middle school students' perceptions, persistence, and performance in mathematical problem solving. Learning Disability Quarterly, 23(3), 215-227. doi: 10.2307/1511165.

Muir, T., Beswick, K., \& Williamson, J. (2008). "I'm not very good at solving problems": an exploration of students' problem solving behaviours. The Journal of Mathematical Behavior, 27(3), 228-241. doi: 10.1016/j.jmathb.2008.04.003.

National Council of Teachers of Mathematics (NCTM). (2010). Why is teaching with problem solving important to student learning? Reston: National Council of Teachers of Mathematics.

Novick, L. R. (1988). Analogical transfer, problem similarity, and expertise. Journal of Experimental Psychology: Learning, Memory, and Cognition, 14(3), 510-520. doi: 10.1037/0278-7393.14.3.510.

OECD. (2016). Pisa 2015 Results. Excellence and equity in education (Volume I). Paris: OECD Publishing.

Op't Eynde, P., De Corte, E., \& Mercken, I. (2004). Pupils' (meta)emotional knowledge and skills in the mathematics classroom. Paper presented at the annual meeting of the American Educational Research Association (AERA), San Diego.

Pekrun, R. (2014). Emotions and learning. Educational Practices Series. Belley, France: International Academy of Education.

Pekrun, R., Goetz, T., Daniels, L. M., Stupnisky, R. H., \& Perry, R. P. (2010). Boredom in achievement settings: control-value antecedents and performance outcomes of a neglected emotion. Journal of Educational Psychology, 102(3), 531-549. doi: 10.1037/a0019243.

Pekrun, R., Goetz, T., \& Frenzel, A.C. (2005). Achievement Emotions Questionnaire-Mathematics (AEQ-M). User's Manual. Unpublished document. University de Munich, Munich.

Piaget, J. (1978). Success and understanding. Cambridge, MA: Harvard University Press.

Pollock, E., Chandler, P., \& Sweller, J. (2002). Assimilating complex information. Learning and Instruction, 12(1), 61-86. doi: 10.1016/S0959-4752(01)00016-0.

Priolet, M. (2014). Enseignement-apprentissage de la résolution de problèmes numériques à l'école élémentaire: un cadre didactique basé sur une approche systémique [Teaching-learning of digital problem-solving in elementary schools: a didactic framework based on a systemic approach]. Education \& Didactique, 8(2), 59-86.

Tzohar-Rozen, M., \& Kramarski, B. (2014). Metacognition, motivation and emotions: contribution of selfregulated learning to solving mathematical problems. Global Education Review, 1(4), 76-95.

Tzohar-Rozen, M., \& Kramarski, B. (2017). Meta-cognition and meta-affect in young students: does it make a difference on mathematical problem solving? Teachers College Record, 119(13).

Van der Sandt, S. (2007). Research framework on mathematics teacher behaviour: Koehler and Grouws' framework revisited. Eurasia Journal of Mathematics, Science \& Technology, 3(4), 343-350.

Van Dooren, W., Verschaffel, L., Greer, B., De Bock, D., \& Crahay, M. (2010). La modélisation des problèmes mathématiques [Modeling mathematical problems]. In M. Crahay \& M. Dutrévis (Eds.), Psychologie des apprentissages scolaires [Psychology of school learning] (2nd ed., pp. 199-220). Bruxelles: De Boeck. 
Van Merriënboer, J. J., \& Sweller, J. (2005). Cognitive load theory and complex learning: recent developments and future directions. Educational Psychology Review, 17(2), 147-177. doi: 10.1007/s10648-0053951-0.

Veenman, M. V. J., Van Hout-Wolters, B., \& Afflerbach, P. (2006). Metacognition and learning: conceptual and methodological considerations. Metacognition and Learning, 1(1), 3-14. doi: 10.1007/s11409006-6893-0.

Wilkins, J. L. (2008). The relationship among elementary teachers' content knowledge, attitudes, beliefs, and practices. Journal of Mathematics Teacher Education, 11(2), 139-164. doi: 10.1007/s10857-0079068-2.

Wolters, C. A., \& Rosenthal, H. (2000). The relation between students' motivational beliefs and their use of motivational regulation strategies. International Journal of Educational Research, 33(7-8), 801-820. doi: 10.1016/S0883-0355(00)00051-3.

Zimmerman, B. J. (2011). Motivational sources and outcomes of self-regulated learning and performance. In B. Zimmerman \& D. Schunk (Eds.), Handbook of self-regulation of learning and performance (pp. 49-64). New York, NY: Routledge.

Zimmerman, B. J., \& Campillo, M. (2003). Motivating self-regulated problem solvers. In J. E. Davidson \& R. J. Sternberg (Eds.), The psychology of problem solving (pp. 233-262). New York, NY: Cambridge University Press.

\section{Appendix A. Training program's features.}

The training program implemented in the present study aimed to develop an expert and reflexive approach to problem solving among students by means of the following components:

(1) Each regular teacher familiarized his/her students with the eight heuristic strategies/stages depicted in Figure 1. This familiarization was performed according to the WWW \& H rule (Veenman et al., 2006), which consists in teaching each heuristic strategy by specifying the what (what it consists of), the why (its usefulness), the when (the most relevant point in the problem-solving process at which to implement it), and the how (the way to implement it correctly);

(2) The teachers used an open-ended methodology to foster diversity of problem representations, modelings, strategies and procedures (Fagnant \& Demonty, 2005);

(3) Students were trained and scaffolded to regulate their own problem-solving process in an increasingly autonomous way;

(4) The non-routine problems chosen were realistic (i.e., problems were anchored in fifth-grade students' experiential worlds), complex (i.e., problems made it necessary to implement a mathematical modeling process), and open-ended (i.e., problems could be correctly represented, modeled, and solved by taking different paths), as suggested by De Corte et al. (2004).

Furthermore, as the objective of this training program was the development of a process to solve non-routine problems, only application problems were selected. Moreover, except for the first problem, which was solved in groups of five students, problems were solved individually and followed by a whole-class discussion. 
Appendix B. Baseline means, standard deviations, and difference analyses between the three groups (Time 1).

\begin{tabular}{|c|c|c|c|c|c|c|c|c|}
\hline \multirow[b]{2}{*}{ Variable } & \multicolumn{2}{|c|}{$\begin{array}{c}\text { "Gradual-all } \\
\text { together" group } \\
(n=86)\end{array}$} & \multicolumn{2}{|c|}{$\begin{array}{c}\text { "Simultaneous" } \\
\text { group } \\
(n=79) \\
\end{array}$} & \multicolumn{2}{|c|}{$\begin{array}{l}\text { Control group } \\
(n=102)\end{array}$} & \multirow[b]{2}{*}{$F(2,264)$} & \multirow[b]{2}{*}{$p$} \\
\hline & $M$ & $S D$ & $M$ & $S D$ & $M$ & $S D$ & & \\
\hline $\begin{array}{l}\text { Performance in problem } \\
\text { solving }\end{array}$ & .36 & .29 & .40 & .32 & .30 & .33 & .332 & .718 \\
\hline Persistence & 3.26 & .39 & 3.16 & .37 & 3.31 & .48 & 2.844 & .060 \\
\hline Building a representation & .38 & .24 & .36 & .22 & .34 & .24 & .294 & .745 \\
\hline Using one's knowledge & .00 & .00 & .00 & .00 & .00 & .00 & I & I \\
\hline Planning & .11 & .19 & .10 & .16 & .09 & .17 & .189 & .828 \\
\hline $\begin{array}{l}\text { Checking the outcome(s) } \\
\text { and the procedure }\end{array}$ & .00 & .00 & .00 & .00 & .00 & .00 & / & / \\
\hline Interpreting the outcome & .15 & .24 & .22 & .29 & .18 & .29 & 1.816 & .165 \\
\hline Positive emotions & 2.23 & .96 & 2.00 & .99 & 2.27 & 1.04 & 1.754 & .175 \\
\hline Negative emotions & 1.98 & .73 & 1.88 & .68 & 1.76 & .61 & 2.198 & .113 \\
\hline Emotion regulation & 2.17 & .43 & 2.18 & .36 & 2.08 & 41 & 1.790 & .169 \\
\hline Emotion expression & 1.48 & .64 & 1.54 & .69 & 1.26 & .56 & 4.880 & $.008^{10}$ \\
\hline Task utility self-persuasion & 3.27 & .76 & 3.03 & .84 & 3.06 & .88 & 1.919 & .149 \\
\hline Negative self-talk & 1.73 & .77 & 2.00 & .77 & 1.83 & .84 & 2.211 & .112 \\
\hline Help-seeking & 2.54 & .75 & 2.38 & .75 & 2.27 & .82 & .484 & .617 \\
\hline Brief attentional relaxation & 2.27 & .80 & 2.25 & .73 & 2.25 & .79 & .016 & .984 \\
\hline Dysfunctional avoidance & 1.80 & .82 & 1.89 & .71 & 1.81 & .79 & .835 & .435 \\
\hline
\end{tabular}

Note. Time $1=$ pre-test $n=$ sample size; $\mathrm{M}=$ mean; $\mathrm{SD}=$ standard deviation.

\footnotetext{
${ }^{10}$ Students in the "gradual-all together" group used the "emotion expression" strategy significantly more than those in the control group $(t(186)=-2.421, p=.017)$. The same behavior was observed for the students in the "simultaneous" group as compared to those in the control group $(t(179)=2.952, p=.004)$.
} 
Appendix C. Baseline means, standard deviations, and difference analyses between the three groups of novice problem-solvers (Time 1).

\begin{tabular}{|c|c|c|c|c|c|c|c|c|}
\hline \multirow[b]{2}{*}{ Variable } & \multicolumn{2}{|c|}{$\begin{array}{c}\text { "Gradual-all } \\
\text { together" group } \\
(n=43)\end{array}$} & \multicolumn{2}{|c|}{$\begin{array}{c}\text { "Simultaneous" } \\
\text { group } \\
(n=43) \\
\end{array}$} & \multicolumn{2}{|c|}{$\begin{array}{l}\text { Control group } \\
\quad(n=43)\end{array}$} & \multirow[b]{2}{*}{$F(2,126)$} & \multirow[b]{2}{*}{$p$} \\
\hline & $M$ & $S D$ & $M$ & $S D$ & $M$ & $S D$ & & \\
\hline $\begin{array}{l}\text { Performance in problem } \\
\text { solving }\end{array}$ & .15 & .14 & .14 & .13 & .14 & .13 & .183 & .833 \\
\hline Persistence & 3.24 & .40 & 3.06 & .36 & 3.21 & .54 & 2.069 & .130 \\
\hline Building a representation & .40 & .28 & .34 & 20 & .32 & .26 & 1.435 & 242 \\
\hline Using one's knowledge & .00 & .00 & .00 & .00 & .00 & .00 & I & I \\
\hline Planning & .04 & .11 & .09 & .17 & .05 & .14 & 1.708 & .185 \\
\hline $\begin{array}{l}\text { Checking the outcome(s) } \\
\text { and the procedure }\end{array}$ & .00 & .00 & .00 & .00 & .00 & .00 & / & I \\
\hline Interpreting the outcome & .08 & .18 & .09 & 20 & .05 & .15 & .708 & .495 \\
\hline Positive emotions & 1.91 & .85 & 1.85 & .94 & 2.23 & 1.05 & 1.840 & .163 \\
\hline Negative emotions & 2.14 & .74 & 2.01 & .75 & 1.92 & .65 & .818 & 444 \\
\hline Emotion regulation & 2.28 & .47 & 2.23 & .38 & 2.19 & .43 & .502 & .606 \\
\hline Emotion expression & 1.45 & .67 & 1.48 & .57 & 1.32 & .68 & .896 & .411 \\
\hline Task utility self-persuasion & 3.25 & .77 & 3.03 & .84 & 3.06 & .92 & 1.843 & .163 \\
\hline Negative self-talk & 1.98 & .92 & 2.10 & .76 & 1.94 & .92 & .663 & .517 \\
\hline Help-seeking & 2.69 & .71 & 2.48 & .76 & 2.5 & .94 & .829 & .439 \\
\hline Brief attentional relaxation & 2.44 & .82 & 2.36 & .81 & 2.34 & .84 & .120 & .887 \\
\hline Dysfunctional avoidance & 1.87 & .93 & 2.00 & .75 & 1.93 & .85 & .191 & .827 \\
\hline
\end{tabular}

Note. Time 1 = pre-test $n=$ sample size; $\mathrm{M}=$ mean; $\mathrm{SD}=$ standard deviation. 
Appendix D. Baseline means, standard deviations, and difference analyses between the three groups of expert problem-solvers (Time 1).

\begin{tabular}{llccccccc}
\hline & $\begin{array}{c}\text { "Gradual-all } \\
\text { together" group } \\
(n=12)\end{array}$ & $\begin{array}{c}\text { "Simultaneous" } \\
\text { group } \\
(n=12)\end{array}$ & $\begin{array}{c}\text { Control group } \\
(n=12)\end{array}$ & & \\
\hline Variable & $M$ & $S D$ & $M$ & $S D$ & $M$ & $S D$ & $F(2,33)$ & $p$ \\
\hline Performance in problem & .81 & .16 & .88 & .08 & .89 & .08 & 1.949 & .159 \\
solving & & & & & & & & \\
Persistence & 3.38 & .40 & 3.32 & .31 & 3.47 & .43 & .485 & .620 \\
Building a representation & .39 & .13 & .31 & .17 & .47 & .26 & 2.152 & .132 \\
Using one's knowledge & .00 & .00 & .00 & .00 & .00 & .00 & $/$ & $/$ \\
Planning & .22 & .30 & .11 & .16 & .11 & .17 & .767 & .472 \\
Checking the outcome(s) & .00 & .00 & .00 & .00 & .00 & .00 & $/$ & $/$ \\
and the procedure & & & & & & & & \\
Interpreting the outcome & .43 & .32 & .54 & .29 & .54 & .20 & 2.795 & .076 \\
Positive emotions & 2.81 & .82 & 2.19 & .99 & 2.39 & 1.04 & 1.280 & .292 \\
Negative emotions & 1.43 & .44 & 1.53 & .43 & 1.65 & .59 & .596 & .557 \\
Emotion regulation & 1.88 & .40 & 2.17 & .34 & 2.04 & .37 & 1.849 & .173 \\
Emotion expression & 1.08 & .19 & 1.83 & .94 & 1.13 & .31 & 6.312 & .005 \\
Task utility self-persuasion & 3.04 & 1.03 & 3.42 & .70 & 3.33 & .91 & .584 & .564 \\
Negative self-talk & 1.53 & .67 & 1.45 & .76 & 1.61 & .61 & .060 & .942 \\
Help-seeking & 1.92 & .63 & 2.33 & .72 & 2.33 & .81 & 1.329 & .279 \\
Brief attentional relaxation & 2.11 & .92 & 2.31 & .50 & 2.39 & .41 & .486 & .620 \\
Dysfunctional avoidance & 1.58 & .82 & 1.58 & .47 & 1.58 & .79 & .054 & .948 \\
\hline
\end{tabular}

Note. Time $1=$ pre-test, $n=$ sample size; $\mathrm{M}=$ mean; $\mathrm{SD}=$ standard deviation.

\footnotetext{
${ }^{11}$ It turned out that the students in the "simultaneous" group used the emotion expression strategy significantly more
} than their counterparts in the control group $(t(22)=-2.984, p=.006)$. 
Appendix E. Repeated measures ANOVAs with the full sample.

\begin{tabular}{|c|c|c|c|c|c|c|c|c|c|}
\hline & \multicolumn{3}{|c|}{ Time 1 and Time 2} & \multicolumn{3}{|c|}{ Time 1 and Time 3} & \multicolumn{3}{|c|}{ Time 2 and Time 3} \\
\hline Variables & $F(2,264)$ & $p$ & $\begin{array}{c}\text { Partial } \\
\eta^{2}\end{array}$ & $F(2,264)$ & $p$ & $\begin{array}{c}\text { Partial } \\
\eta^{2}\end{array}$ & $F(2,264)$ & $p$ & $\begin{array}{c}\text { Partial } \\
\eta^{2} \\
\end{array}$ \\
\hline $\begin{array}{l}\text { Performance in } \\
\text { problem solving }\end{array}$ & .484 & .617 & & .038 & .962 & & .198 & .821 & \\
\hline Persistence & 8.079 & $<.001$ & .010 & .661 & .517 & & 2.591 & .079 & \\
\hline $\begin{array}{l}\text { Building a } \\
\text { representation }\end{array}$ & 32.319 & $<.001$ & .21 & 35.457 & $<.001$ & .24 & 3.959 & .021 & .03 \\
\hline $\begin{array}{l}\text { Using one's } \\
\text { knowledge }\end{array}$ & 28.573 & $<.001$ & .19 & 16.106 & $<.001$ & .12 & .616 & .541 & \\
\hline Planning & 18.272 & $<.001$ & .13 & 15.361 & $<.001$ & .12 & .178 & .837 & \\
\hline $\begin{array}{l}\text { Checking the } \\
\text { outcome(s) and } \\
\text { the procedure }\end{array}$ & .474 & .623 & & .516 & .597 & & .799 & 451 & \\
\hline $\begin{array}{l}\text { Interpreting the } \\
\text { outcome }\end{array}$ & .376 & 687 & & 1.396 & .250 & & 1.855 & .159 & \\
\hline $\begin{array}{l}\text { Positive } \\
\text { emotions }\end{array}$ & 1.787 & 170 & & .475 & .623 & & .557 & .574 & \\
\hline $\begin{array}{l}\text { Negative } \\
\text { emotions }\end{array}$ & .715 & 491 & & .707 & .494 & & 1.584 & 208 & \\
\hline $\begin{array}{l}\text { Emotion } \\
\text { regulation }\end{array}$ & 1.585 & 208 & & 2.292 & .103 & & .920 & 400 & \\
\hline $\begin{array}{l}\text { Task utility } \\
\text { self-persuasion }\end{array}$ & 2.235 & .110 & & 1.638 & .197 & & .556 & .574 & \\
\hline $\begin{array}{l}\text { Brief attentional } \\
\text { relaxation }\end{array}$ & 1.776 & .172 & & .007 & .993 & & 1.404 & 248 & \\
\hline Help-seeking & 2.763 & $.066^{t}$ & .03 & 4.543 & .012 & .04 & 1.788 & .170 & \\
\hline $\begin{array}{l}\text { Emotion } \\
\text { expression }\end{array}$ & .120 & .887 & & 1.787 & .170 & & 3.481 & .033 & .03 \\
\hline $\begin{array}{l}\text { Negative self- } \\
\text { talk }\end{array}$ & 4.139 & .017 & .04 & 1.562 & .212 & & 1.320 & 269 & \\
\hline $\begin{array}{l}\text { Dysfunctional } \\
\text { avoidance }\end{array}$ & .636 & .530 & & 1.120 & .328 & & .442 & .643 & \\
\hline
\end{tabular}

Note. Time 1 = pre-test; Time 2 = post-test; Time 3 = follow-up test. 
Appendix F. Repeated measures ANOVAs for novice problem-solvers.

\begin{tabular}{|c|c|c|c|c|c|c|c|c|c|}
\hline \multirow[b]{2}{*}{ Variables } & \multicolumn{3}{|c|}{ Time 1 and Time 2} & \multicolumn{3}{|c|}{ Time 1 and Time 3} & \multicolumn{3}{|c|}{ Time 2 and Time 3} \\
\hline & $F(2,126)$ & $p$ & $\begin{array}{c}\text { Partial } \\
\eta^{2}\end{array}$ & $F(2,126)$ & $p$ & $\begin{array}{c}\text { Partial } \\
\eta^{2}\end{array}$ & $F(2,126)$ & $p$ & $\begin{array}{c}\text { Partial } \\
\eta^{2}\end{array}$ \\
\hline $\begin{array}{l}\text { Performance in } \\
\text { problem solving }\end{array}$ & 1.196 & 306 & & .152 & .859 & & 1.420 & .246 & \\
\hline Persistence & 5.799 & .004 & .13 & .503 & .606 & & 4.624 & .013 & .12 \\
\hline $\begin{array}{l}\text { Building a } \\
\text { representation }\end{array}$ & 16.753 & $<.001$ & .21 & 14.428 & $<.001$ & .19 & .046 & .955 & \\
\hline $\begin{array}{l}\text { Using one's } \\
\text { knowledge }\end{array}$ & 9.531 & $<.001$ & .14 & 6.669 & .002 & .10 & .102 & .903 & \\
\hline Planning & 8.162 & $<.001$ & .12 & 7.908 & .001 & .12 & .175 & .840 & \\
\hline $\begin{array}{l}\text { Checking the } \\
\text { outcome(s) and the } \\
\text { procedure }\end{array}$ & 2.304 & .104 & & .988 & .375 & & .349 & .706 & \\
\hline $\begin{array}{l}\text { Interpreting the } \\
\text { outcome }\end{array}$ & .452 & .637 & & .755 & .472 & & 1.980 & .143 & \\
\hline Positive emotions & 1.176 & .313 & & .638 & .530 & & .113 & .893 & \\
\hline Negative emotions & 2.168 & .120 & & .406 & .668 & & 2.257 & .110 & \\
\hline Emotion regulation & 1.235 & .295 & & 2.102 & .127 & & 1.266 & 286 & \\
\hline $\begin{array}{l}\text { Task utility self- } \\
\text { persuasion }\end{array}$ & 3.769 & .026 & .07 & 2.270 & .108 & & .606 & .547 & \\
\hline $\begin{array}{l}\text { Brief attentional } \\
\text { relaxation }\end{array}$ & 1.569 & .213 & & .009 & .992 & & .852 & .429 & \\
\hline Help-seeking & 4.591 & .011 & .08 & 6.995 & .001 & .11 & 1.562 & .214 & \\
\hline Emotion expression & .101 & .904 & & 1.651 & .196 & & 2.215 & .114 & \\
\hline Negative self-talk & 4.164 & .018 & .08 & 2.178 & .118 & & 3.195 & .045 & .06 \\
\hline $\begin{array}{l}\text { Dysfunctional } \\
\text { avoidance }\end{array}$ & .034 & .967 & & .536 & .587 & & .695 & .501 & \\
\hline
\end{tabular}

Note. Time 1 = pre-test; Time 2 = post-test; Time 3 = follow-up test. 
Appendix G. Repeated measures ANOVAs for expert problem-solvers.

\begin{tabular}{|c|c|c|c|c|c|c|c|c|c|}
\hline \multirow[b]{2}{*}{ Variables } & \multicolumn{3}{|c|}{ Time 1 and Time 2} & \multicolumn{3}{|c|}{ Time 1 and Time 3} & \multicolumn{3}{|c|}{ Time 2 and Time 3} \\
\hline & $F(2,34)$ & $p$ & $\begin{array}{c}\text { Partial } \\
\eta^{2}\end{array}$ & $F(2,34)$ & $p$ & $\begin{array}{c}\text { Partial } \\
\eta^{2}\end{array}$ & $F(2,34)$ & $p$ & $\begin{array}{c}\text { Partial } \\
\eta^{2} \\
\end{array}$ \\
\hline $\begin{array}{l}\text { Performance in } \\
\text { problem solving }\end{array}$ & 1.517 & .235 & & .353 & .706 & & .206 & .815 & \\
\hline Persistence & 7.385 & .007 & .53 & 3.692 & .041 & .24 & .692 & .536 & \\
\hline $\begin{array}{l}\text { Building a } \\
\text { representation }\end{array}$ & 13.184 & $<.001$ & .45 & 8.010 & .002 & .38 & 1.039 & .368 & \\
\hline $\begin{array}{l}\text { Using one's } \\
\text { knowledge }\end{array}$ & 10.895 & $<.001$ & .41 & 3.183 & .058 & .20 & .127 & .881 & \\
\hline Planning & 9.111 & .001 & .36 & 3.621 & .040 & .21 & 1.282 & 294 & \\
\hline $\begin{array}{l}\text { Checking the } \\
\text { outcome(s) and the } \\
\text { procedure }\end{array}$ & .956 & .395 & & / & / & & I & / & \\
\hline $\begin{array}{l}\text { Interpreting the } \\
\text { outcome }\end{array}$ & .946 & .398 & & 1.038 & .368 & & .195 & .824 & \\
\hline Positive emotions & 1.387 & .269 & & .203 & .817 & & .849 & .440 & \\
\hline Negative emotions & .195 & .824 & & 1.263 & 299 & & 2.230 & .129 & \\
\hline Emotion regulation & .299 & .744 & & 1.501 & .242 & & 1.279 & .298 & \\
\hline $\begin{array}{l}\text { Task utility self- } \\
\text { persuasion }\end{array}$ & .737 & .489 & & 1.948 & .164 & & 1.363 & .276 & \\
\hline $\begin{array}{l}\text { Brief attentional } \\
\text { relaxation }\end{array}$ & .490 & .619 & & .645 & .533 & & 1.378 & .272 & \\
\hline Help-seeking & .253 & .778 & & .376 & .691 & & .100 & .905 & \\
\hline Emotion expression & .931 & .408 & & .760 & .478 & & .221 & .804 & \\
\hline Negative self-talk & .053 & .948 & & .573 & .571 & & .012 & .988 & \\
\hline $\begin{array}{l}\text { Dysfunctional } \\
\text { avoidance }\end{array}$ & .121 & .886 & & .177 & .839 & & .117 & .890 & \\
\hline
\end{tabular}

Note. Time 1 = pre-test; Time 2 = post-test; Time 3 = follow-up test. 